\title{
An exploration of the dynamic longitudinal relationship between mental health and alcohol consumption: a prospective cohort study
}

\author{
Steven Bell ${ }^{*}$ and Annie Britton
}

\begin{abstract}
Background: Despite intense investigation, the temporal sequence between alcohol consumption and mental health remains unclear. This study explored the relationship between alcohol consumption and mental health over multiple occasions, and compared a series of competing theoretical models to determine which best reflected the association between the two.
\end{abstract}

Methods: Data from phases 5 (1997 to 1999), 7 (2002 to 2004), and 9 (2007 to 2009) of the Whitehall II prospective cohort study were used, providing approximately 10 years of follow-up for 6,330 participants (73\% men; mean \pm SD age $55.8 \pm 6.0$ years). Mental health was assessed using the Short Form (SF)-36 mental health component score. Alcohol consumption was defined as the number of UK units of alcohol drunk per week. Four dynamic latent change score models were compared: 1) a baseline model in which alcohol consumption and mental health trajectories did not influence each other, 2) and model in which alcohol consumption influenced changes in mental health but mental health exerted no effect on changes in drinking and 3) vice versa, and (4) a reciprocal model in which both variables influenced changes in each other.

Results: The third model, in which mental health influenced changes in alcohol consumption but not vice versa, was the best fit. In this model, the effect of previous mental health on upcoming change in alcohol consumption was negative $(\gamma=-0.31,95 \% \mathrm{Cl}-0.52$ to -0.10$)$, meaning that those with better mental health tended to make greater reductions (or shallower increases) in their drinking between occasions.

Conclusions: Mental health appears to be the leading indicator of change in the dynamic longitudinal relationship between mental health and weekly alcohol consumption in this sample of middle-aged adults. In addition to fuelling increases in alcohol consumption among low-level consumers, poor mental health may also be a maintaining factor for heavy alcohol consumption. Future work should seek to examine whether there are critical levels of alcohol intake at which different dynamic relationships begin to emerge between alcohol-related measures and mental health.

Keywords: Alcohol, Mental health, Longitudinal, Reciprocal, Self-medication, Temporality

\section{Background}

Alcohol consumption [1,2] and mental health [3-5] are two of the biggest public health issues facing modern society. The relationship between alcohol consumption and mental health has been documented extensively [6-13], and there have been several ways proposed as to how the relationship may operate [14]. Plausible biological

\footnotetext{
* Correspondence: steven.bell@ucl.ac.uk

Research Department of Epidemiology and Public Health, University College London, 1-19 Torrington Place, London, UK
}

mechanisms for hazardous alcohol consumption leading to depression include alcohol reducing white and gray matter volumes, as well as influencing neurotransmitter functioning [15]. Changes in white and gray matter volume $[16,17]$, and the microstructure of nerve fibers [18] are thought to be related to major depression, while the dysregulation of GABAergic [19,20], dopaminergic [21], and serotonergic $[22,23]$ systems are widely supported hypotheses in the etiology of depression. Hazardous alcohol consumption can create tension in home/work 
environments [24], which may exacerbate marital disputes [25], lead to job loss [26], and result in other stressful scenarios, which in turn can lead to poor mental health. Clinical studies have also demonstrated that individuals treated for alcohol dependence show marked decreases in symptoms of poor mental health following a period of abstinence [27] suggesting that alcohol may be the primary causal factor. Theoretical explanations for poor mental health influencing alcohol intake include the use of alcohol as a coping mechanism for tension and depression/ anxiety [28-32]. A meta-analysis of literature around the 'self-medication' hypothesis found that depression can lead to increased alcohol consumption, and then progression to alcohol-use disorders [33].

The current evidence base is mixed; some authors have found that the driving force is alcohol, while others have concluded that it is mental health. It is also hypothesized that dynamic feedback cycles contribute to the escalation of alcohol consumption and worsening mental health [34]; that is, people may become depressed or anxious and turn to alcohol, which causes them to become more depressed or anxious, which eventually fuels further drinking, or the reverse may occur, with drinking leading to symptoms of anxiety or depression, which encourage further drinking. Yet, few studies have empirically tested this theory and those that have are limited by the methods used to try to capture the dynamic interplay between both variables over time [35] (e.g. not taking into account repeated measures of both variables in the same model). Using repeated longitudinal data on both alcohol consumption and mental health symptoms would allow for hypotheses of leading indicators of change (that is, alcohol consumption driving changes in mental health, or vice versa) as well as reciprocal relationships to be tested. Understanding the temporal sequence of the relationship between the two processes over time is important to public health because it will allow for interventions/prevention strategies to be tailored more effectively.

Furthermore, studies on alcohol consumption and mental health have mostly been concerned with the comorbid relationship between clinical disorders [10], not on subsyndrome symptoms of mental health (that is. pre-clinical manifestations), which make up a greater proportion of the overall burden of mental health [36] or on the drinking habits of the general population. Previous studies have also tended to focus on the transition or maintenance of a clinical state or binary 'heavy drinker' or 'symptoms of mental health problems' $[37,9]$. As the trajectory from disease free to clinical disorder is not as simple as moving from one state to another but is instead characterized by an escalation of symptoms and behaviors, it might be argued that other studies have failed to effectively capture the 'true' longitudinal relationship between mental health and alcohol consumption. Knowing how the relationship between alcohol consumption and mental health operates prior to the development of clinical disorders would allow for primary prevention strategies to be targeted more effectively.

The purpose of this study was therefore to address these limitations by exploring the longitudinal relationship between alcohol consumption and mental health symptoms jointly over multiple occasions in a general population setting, and to compare several competing theoretical models to determine which best reflected the association between these two factors.

\section{Materials and methods The Whitehall II study}

The Whitehall II prospective cohort study started with a sample of 10,308 British civil servants $(6,895$ men and 3,413 women), who were aged 34 to 56 years at entry into the study (1985 to 88) [38]. The current investigation uses of data from three clinical phases: 5 (1997 to 1999; referred to hereafter as 'baseline'), 7 (2002 to 2004) and 9 (2007 to 2009). At baseline, the total number of eligible participants was 7,870 . Those who had not consumed alcohol in the year before baseline and additionally those with missing values for either alcohol consumption or mental health variables at baseline were excluded from the analytic sample $(\mathrm{n}=548$ and $\mathrm{n}=1,036$ respectively; categories were not mutually exclusive). This provided approximately 10 years of follow-up information for 6,330 participants who had consumed alcohol in the year before baseline.

The University College London Medical School Committee on the ethics of human research approved the Whitehall II study.

\section{Assessment of alcohol consumption}

Participants were asked to report the number of drinks they had consumed in the previous week, quoting separately for beer/cider (pints), wine (glasses), and spirits (measures). Drinks were converted into UK units of alcohol (one unit is equivalent to $8 \mathrm{~g}$ of ethanol) using a conservative estimate of one UK unit for each measure of spirits and glass of wine, and two UK units for each pint of beer. These converted measurements were then summed to define the total weekly number of UK units consumed.

\section{Assessment of mental health}

Mental health (combining symptoms of depression and anxiety) was assessed using the mental health component score $[39,40]$ (MCS) of the Short Form (SF)-36 questionnaire [41]. The SF-36 refers to symptoms experienced in the previous 4 weeks. The MCS has been validated using UK data sources [42], and reliability estimates typically exceed values of 0.90 for Cronbach's $\alpha$ [39]. The MCS uses a scale of 0 to 100, with higher scores indicating better functioning. 


\section{Covariates}

Adjustment was made for several baseline covariates, including age, sex, ethnicity, socioeconomic status, marital status, highest educational qualification, economic activity, social network [43], smoking status, level of physical activity [44]. and use of anti-depressant medication. Problematic alcohol consumption (defined by the CAGE questionnaire [45]) was used to adjust for the possibility that problem drinking may be driving any observed relationship [46].

Poor physical health could influence both alcohol consumption $[47,48]$ and mental health [49] trajectories. Therefore, general physical health was accounted for by adjusting for several chronic conditions. A combination of self-report and validated clinical health events [50] were included, such as self-reported long-standing physical illness and belonging to the lowest sex-specific SF-36 physical health component quartile [51], as well as known diabetes mellitus, coronary heart disease (CHD), stroke, transient ischemic attack (TIA), total serum cholesterol, systolic and diastolic blood pressure, resting heart rate over 80 beats/min [52], and body mass index (BMI).

\section{Statistical analysis}

Bivariate latent change score (LCS) models [35,53-57] were used to explore the dominant temporal sequence in the longitudinal relationship between alcohol consumption and mental health symptoms. LCS models are an extension of standard growth curve models [58] (also referred to as random effects models) and acknowledge that repeated measures on the same individual are correlated. A general overview of the underlying assumptions and specification of LCS models are presented (see Additional file 1), but a comprehensive outline of the mathematical and statistical properties [55,57], as well as a comparison of LCS models with other multivariate longitudinal models [35] can be found elsewhere.

Briefly, there are three primary parameters of interest: 1 ) the slope parameter $(\alpha)$, which refers to the additive sum of changes during follow-up; 2) the autoproportional parameter $(\beta)$, which refers to the lagged effect of a variable on an upcoming change in itself (self-feedback); and 3) the coupling parameter $(\gamma)$, which describes the lagged effect of one variable on the upcoming change in the alternate variable.

Both the intercept and the slope were fitted as random effects, allowing for them to vary between individuals. Intercepts and slopes (as well as their random effects) were correlated $(\rho)$ both within a single process (for example, the alcohol consumption intercept with the alcohol slope) and between processes (for example, the mental health intercept with the alcohol slope). Intercepts and slopes were estimated conditional on the baseline covariates described above.

Four separate models were estimated: 1) no coupling (baseline) model; 2) alcohol consumption producing change in mental health model; 3) mental health producing change in alcohol consumption model; and 4) dynamic/reciprocal change model. Nested models were compared to determine the best-fitting model (that is, to justify the inclusion of either or both coupling parameters over a baseline model that did not contain them) using a $\chi^{2}$ difference test.

The relative fit of the hypothesized models compared with the observed data was assessed using the TuckerLewis index (TLI), the comparative fit index (CFI), and the root mean squared error of approximation (RMSEA). Cut-off values close to 0.95 were used to determine a good fit for TLI and CFI, while a cut-off value close to 0.06 was used for RMSEA [59].

Models were estimated in Mplus v6.12 [60] using the full information maximum likelihood (FIML) estimator [61]. An $\alpha$ level of 0.05 was considered statistically significant for all analyses.

\section{Results}

\section{Sample composition}

Table 1 displays descriptive statistics for the complete analytic sample (based on observed information only). The mean age of participants was 56 years, over $70 \%$ were male, and approximately $6 \%$ were non-white. Most were of high to intermediate socioeconomic status, almost four-fifths were married or cohabiting, over $60 \%$ had post-secondary or university level qualifications, and around 65 were economically active. Almost 11\% were current smokers, $11 \%$ were identified as problem drinkers, and $70 \%$ were physically active. In terms of physical health, $6 \%$ of the sample had known CHD, $4 \%$ had known diabetes mellitus, $0.5 \%$ had experienced a stroke, $0.7 \%$ had experienced a TIA, almost 3\% were currently being prescribed anti-depressant medication, and approximately half reported a long-standing illness.

At baseline, participants consumed on average 14.5 UK units of alcohol per week, and this figure had reduced to 11 UK units by the end of follow-up. Mental health scores started at an average of 51 and increased to 54 (a random selection of observed (A) mental health and (B) alcohol consumption trajectories are displayed in Figure 1).

\section{Regression estimates}

Indices related to model fit and statistics concerning model comparison are shown in Table 2. All models specified were well fitting according to commonly accepted thresholds of model fit as outlined above [59]. Detailed estimates for the best-fitting model are presented in Table 3, while only the fixed effect parameters are presented for other models specified in Table 4 (random effects for these models can be found in Additional file 2: Table S2A).

As the association was robust to adjustment for confounding factors, only the fully adjusted estimates will 
Table 1 Sample characteristics

\begin{tabular}{|c|c|c|}
\hline & $\mathbf{n}$ & $\%$ or mean $\pm S D$ \\
\hline \multicolumn{3}{|l|}{ MCS } \\
\hline Phase 5 & 6,330 & $51.1 \pm 9.4$ \\
\hline Phase 7 & 5,436 & $52.4 \pm 8.8$ \\
\hline Phase 9 & 5,195 & $53.8 \pm 8.0$ \\
\hline \multicolumn{3}{|l|}{ UK units of alcohol } \\
\hline Phase 5 & 6,330 & $14.6 \pm 15.2$ \\
\hline Phase 7 & 5,508 & $13.0 \pm 13.0$ \\
\hline Phase 9 & 5,215 & $11.1 \pm 11.3$ \\
\hline Age, years & 6,330 & $55.8 \pm 6.0$ \\
\hline \multicolumn{3}{|l|}{ Sex } \\
\hline Male & 4,594 & 72.6 \\
\hline Female & 1,736 & 27.4 \\
\hline Total & 6,330 & \\
\hline \multicolumn{3}{|l|}{ Ethnicity } \\
\hline White & 5,966 & 94.25 \\
\hline Non-white & 364 & 5.75 \\
\hline Total & 6,330 & \\
\hline \multicolumn{3}{|l|}{ SES } \\
\hline High & 2,852 & 45.3 \\
\hline Intermediate & 2,731 & 43.4 \\
\hline Low & 713 & 11.3 \\
\hline Total & 6,296 & \\
\hline \multicolumn{3}{|l|}{ Marital status } \\
\hline Married/cohabiting & 4,861 & 79.6 \\
\hline Other & 1,248 & 20.4 \\
\hline Total & 6,109 & \\
\hline \multicolumn{3}{|l|}{ Education } \\
\hline University & 2,176 & 36.4 \\
\hline Post-secondary & 1,648 & 27.5 \\
\hline Secondary & 1,558 & 26.0 \\
\hline No qualifications & 604 & 10.1 \\
\hline Total & 5,986 & \\
\hline \multicolumn{3}{|l|}{ Economic activity } \\
\hline Active & 4,123 & 65.2 \\
\hline Inactive & 2,203 & 34.8 \\
\hline Total & 6,326 & \\
\hline \multicolumn{3}{|l|}{ Current smoker } \\
\hline No & 5,539 & 89.4 \\
\hline Yes & 654 & 10.6 \\
\hline Total & 6,193 & \\
\hline \multicolumn{3}{|c|}{ Problem drinking (CAGE case) } \\
\hline No & 5,531 & 89.0 \\
\hline Yes & 684 & 11.0 \\
\hline Total & 6,215 & \\
\hline
\end{tabular}

Table 1 Sample characteristics (Continued)

\begin{tabular}{|c|c|c|}
\hline \multicolumn{3}{|l|}{ Physical activity } \\
\hline Active & 3,405 & 54.16 \\
\hline Moderately active & 1,057 & 16.78 \\
\hline Inactive & 1,837 & 29.16 \\
\hline Total & 6,299 & \\
\hline Network score & 6,053 & $7.3 \pm 3.0$ \\
\hline \multicolumn{3}{|l|}{$\mathrm{CHD}$} \\
\hline No & 5,948 & 94.0 \\
\hline Yes & 382 & 6.0 \\
\hline Total & 6,330 & \\
\hline \multicolumn{3}{|l|}{ Known diabetes } \\
\hline No & 6,076 & 96.0 \\
\hline Yes & 254 & 4.0 \\
\hline Total & 6,330 & \\
\hline \multicolumn{3}{|l|}{ Anti-depressant medication } \\
\hline No & 6,149 & 97.3 \\
\hline Yes & 171 & 2.7 \\
\hline Total & 6,320 & \\
\hline \multicolumn{3}{|c|}{ Poor self-reported physical health } \\
\hline No & 4,821 & 76.2 \\
\hline Yes & 1,509 & 23.8 \\
\hline Total & 6,330 & \\
\hline \multicolumn{3}{|l|}{ Long-standing illness } \\
\hline No & 3,248 & 51.4 \\
\hline Yes & 3,075 & 48.6 \\
\hline Total & 6,323 & \\
\hline \multicolumn{3}{|l|}{ Stroke } \\
\hline No & 6,301 & 99.5 \\
\hline Yes & 29 & 0.5 \\
\hline Total & 6,330 & \\
\hline \multicolumn{3}{|l|}{ TIA } \\
\hline No & 6,287 & 99.3 \\
\hline Yes & 43 & 0.7 \\
\hline Total & 6,330 & \\
\hline \multicolumn{3}{|l|}{ Resting heart rate $>80 \mathrm{bpm}$} \\
\hline No & 4,969 & 88.15 \\
\hline Yes & 668 & 11.85 \\
\hline Total & 5,637 & \\
\hline BMl & 4,916 & $26.1 \pm 3.9$ \\
\hline Serum cholesterol, mmol/l & 5,622 & $5.9 \pm 1.1$ \\
\hline \multicolumn{3}{|l|}{ Blood pressure, mmHg } \\
\hline Systolic & 5,669 & $123.1 \pm 16.4$ \\
\hline Diastolic & 5,669 & $77.6 \pm 10.6$ \\
\hline
\end{tabular}

BMI, body mass index; bpm, beats per minute; $\mathrm{CHD}$, coronary heart disease; MCS, mental health component score; SES, socioeconomic status; TIA, transient ischemic attack. 

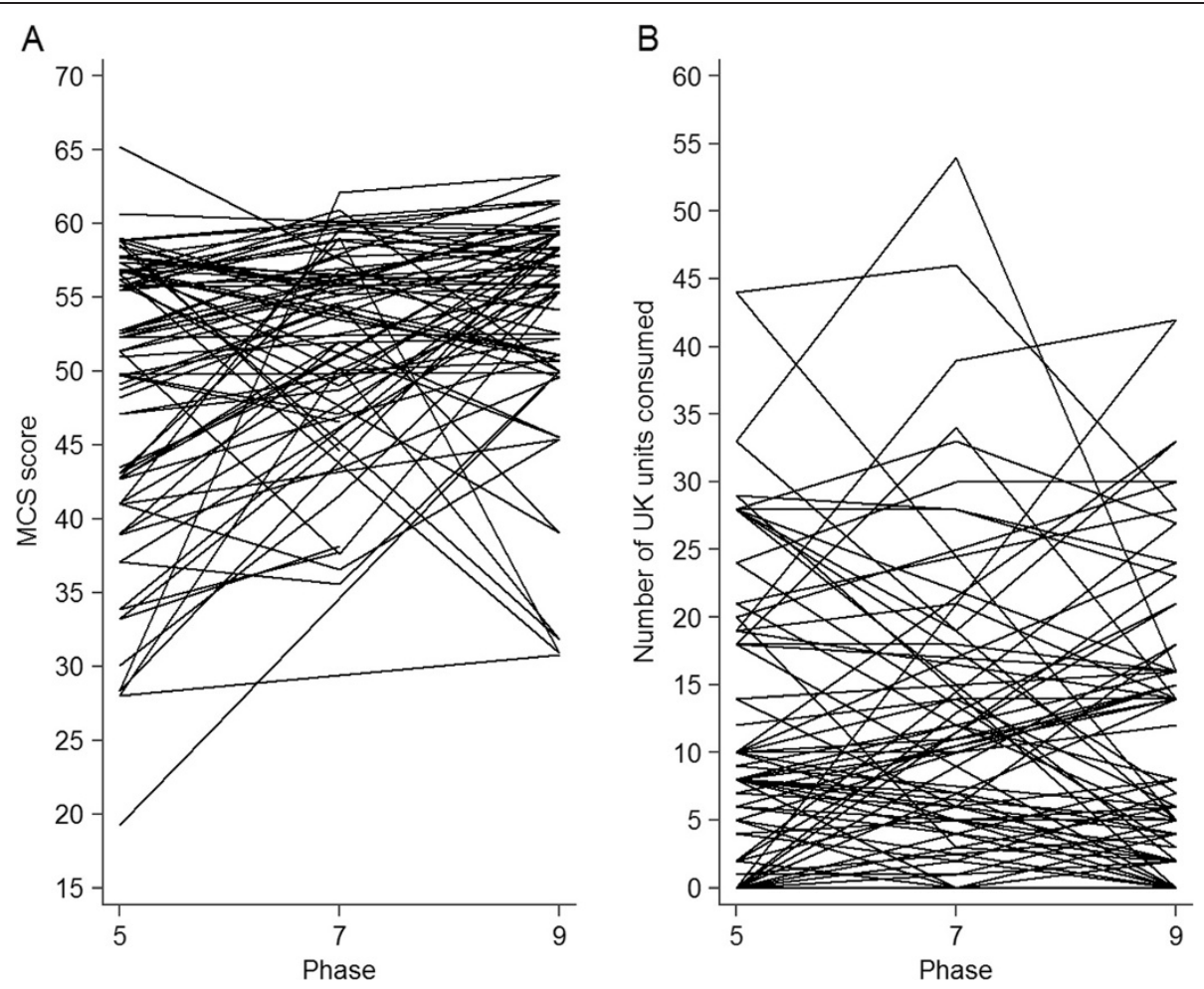

Figure 1 Spaghetti plots of the observed longitudinal trajectories of mental health symptoms (panel A) and alcohol consumption (panel B) in a random sample $(n=50)$ of participants in the Whitehall II study.

be discussed here (but age and sex, as well as fully adjusted estimates are presented). Furthermore, only parameters of primary interest will be highlighted.

\section{No coupling (baseline) model}

The top third of Table 4 refers to the baseline model (in which alcohol use and mental health do not influence changes in each other). A significant autoproportional effect for alcohol consumption was found $(\beta=-0.42$, CI -0.52 to -0.33 ) but not for mental health. The coefficient was negative, indicating that those drinking more made greater reductions in their alcohol consumption between phases.

\section{Alcohol consumption producing change in mental health model} The middle third of Table 4 shows estimates for a model where alcohol use affected upcoming change in mental health, but mental health had no effect on change in alcohol consumption. The alcohol autoproportional effect was significant $(\beta=-0.43, \mathrm{CI}-0.52$ to -0.33$)$ but not the mental health parameter. The coupling parameter was also non-significant. This model was compared with the baseline model, but offered no significant improvement in fit (Table 2).

Mental health producing change in alcohol consumption model The estimates concerning the model in which mental health scores affected upcoming change in alcohol consumption, but alcohol consumption had no effect on changes in mental health are presented in Table 3. A significant autoproportional effect was found for alcohol consumption ( $\beta=-0.50$, CI -0.60 to -0.40$)$ but not mental health. The coupling parameter was significant $(\gamma=-0.31, \mathrm{CI}-0.52$ to -0.10 ) in this instance, and was negative, meaning that those with better mental health made greater reductions in their drinking. This model was an improvement over the baseline model (Table 2; $P<0.01$ ).

\section{Dynamic/reciprocal change model}

The final third of Table 4 shows estimates from a model in which both alcohol consumption and mental health scores are able to affect change in the alternative variable. As in previous models, a significant autoproportional effect was found for alcohol consumption $(\beta=-0.50, \mathrm{CI}-0.59$ to -0.40 ) but not mental health. The coupling parameter from previous phase mental health to change in alcohol consumption remained significant $(\gamma=-0.31, \mathrm{CI}-0.52$ to -0.11 ), whereas the effect of previous occasion alcohol consumption was not associated with changes in mental health. This model offered little improvement in fit over the previous model (Table 2), indicating that the model in which mental health influences changes in alcohol consumption but not vice versa is the best fit to the data.

It is necessary to jointly interpret the estimates in Table 3 to fully appreciate the dynamics of the alcohol 
Table 2 Model fit indices and comparison of LCS models for total weekly alcohol consumption and mental health in the Whitehall II study

\begin{tabular}{|c|c|c|c|c|}
\hline & Baseline & Alcohol $\rightarrow \Delta$ MCS & MCS $\rightarrow \Delta$ alcohol & Reciprocal \\
\hline \multicolumn{5}{|l|}{ Age and sex adjusted } \\
\hline \multicolumn{5}{|l|}{ Fit statistics } \\
\hline Log likelihood & -146158.161 & -146158.041 & -146155.151 & -146154.760 \\
\hline$x^{2}(d f)$ & $274.233(12)$ & $273.995(11)$ & $268.214(11)$ & $267.432(10)$ \\
\hline RMSEA & 0.059 & 0.061 & 0.061 & 0.064 \\
\hline $\mathrm{AlC}$ & 292380.321 & 292382.083 & 292376.302 & 292377.520 \\
\hline SSA BIC & 292494.731 & 292500.068 & 292494.288 & 292499.081 \\
\hline $\mathrm{CFI}$ & 0.982 & 0.982 & 0.982 & 0.982 \\
\hline TLI & 0.959 & 0.955 & 0.956 & 0.952 \\
\hline \multicolumn{5}{|c|}{ Model comparison (difference in $x^{2}$ fit (df)) } \\
\hline Versus baseline & - & $0.238(1), P=0.63$ & $6.019(1), P=0.01$ & $6.801(2), P=0.03$ \\
\hline Versus previous best & - & - & - & $0.782(1), P=0.38$ \\
\hline \multicolumn{5}{|l|}{ Fully adjusted } \\
\hline \multicolumn{5}{|l|}{ Fit statistics } \\
\hline Log likelihood & -243989.314 & -243989.108 & -243985.355 & -243984.851 \\
\hline$x^{2}(d f)$ & $328.239(54)$ & $327.827(53)$ & $320.320(53)$ & $319.312(52)$ \\
\hline RMSEA & 0.028 & 0.029 & 0.028 & 0.028 \\
\hline AIC & 488798.629 & 488800.217 & 488792.710 & 488793.702 \\
\hline SSA BIC & 490264.509 & 490269.672 & 490262.165 & 490266.732 \\
\hline $\mathrm{CFI}$ & 0.983 & 0.983 & 0.984 & 0.984 \\
\hline TLI & 0.952 & 0.951 & 0.953 & 0.952 \\
\hline \multicolumn{5}{|c|}{ Model comparison (difference in $x^{2}$ fit (df)) } \\
\hline Versus baseline & - & $0.412(1), P=0.52$ & $7.919(1), P<0.01$ & $8.927(2), P<0.01$ \\
\hline Versus previous best & - & - & - & $1.008(1), P=0.32$ \\
\hline
\end{tabular}

AIC, Akaike information criterion; CFI, comparative fit index; df, degrees of freedom; LCS, latent change score; MCS, mental health component score; RMSEA, root mean square error of approximation; SSA BIC, sample size adjusted Bayesian information criterion; TLI, Tucker-Lewis index.

use and mental health system because parameters are dependent on each other $[54,55,57,62]$. Concentrating on the fully adjusted estimates, to predict change, Equation 4 in Additional file 1 would be adapted to remove the coupling parameter from previous phase alcohol consumption to changes in mental health, resulting in a final change equation (conditional on other covariates in the model; for coefficients, see Additional file 3: Table S3A) of:

$$
\begin{aligned}
& \Delta \text { Alcohol }_{i t}=23.31 \pm 4.86-0.50 \times \text { Alcohol }_{i t-1} \\
& -0.31 \times M C S_{i t-1} \\
& \Delta M C S_{i t}=7.20 \pm 1.37-0.11 \times M C S_{i t-1}
\end{aligned}
$$

The expected change in both mental health scores and UK units of alcohol consumed between phases can then be plotted within a vector field [63] (Figure 2). This figure displays the direction and magnitude of change in both variables for a given set of starting co-ordinates. The ellipsoid reflects where $95 \%$ of the data lay.

\section{Discussion}

\section{Summary and interpretation of findings}

A series of LCS models were estimated to test lag-leading and reciprocal relationships between weekly number of UK units consumed and mental health. In both minimally adjusted and fully adjusted models, it was found that a model in which mental health was specified as the leading indicator of change gave the best fit (Table 2, Table 3).

Plotting the parameters of this model in a vector field (Figure 2) demonstrates the complex relationship between weekly alcohol consumption and mental health, and also helps to visualize the correlation between the mental health intercept and alcohol slope, which is difficult to interpret in isolation. It shows that participants who initially had poor mental health and low alcohol consumption increased their consumption between phases, whereas those with good to adequate mental health who drank at higher levels tended to decrease their consumption between phases while their mental health scores remained relatively stable. Furthermore, it shows that participants with poor mental health 


\begin{tabular}{|c|c|c|c|c|}
\hline \multirow[t]{2}{*}{ MCS $\rightarrow \Delta$ alcohol model } & \multicolumn{2}{|l|}{ Age and sex adjusted } & \multicolumn{2}{|l|}{ Fully adjusted $^{\text {b }}$} \\
\hline & Alcohol & MCS & Alcohol & MCS \\
\hline \multicolumn{5}{|l|}{ Fixed effects } \\
\hline Intercept & 17.11 (16.69 to 17.53$)$ & $51.54^{* * *}$ (51.28 to 51.79$)$ & 17.58 (16.64 to 18.52$)$ & $53.41^{* * *}$ (52.81 to 54.00$)$ \\
\hline Slope (a) & $21.46^{* *}$ (8.50 to 34.43 ) & $4.96(-8.62$ to 18.54$)$ & $23.31^{* * *}(11.00$ to 35.62$)$ & $7.20(-5.55$ to 19.96$)$ \\
\hline Autoproportional ( $\beta$ ) & $-0.50^{* * *}(-0.61$ to -0.40$)$ & $-0.07(-0.33$ to 0.19$)$ & $-0.50^{* * *}(-0.60$ to -0.41$)$ & $-0.11(-0.35$ to 0.12$)$ \\
\hline Coupling ( $(\gamma)$ & - & $-0.30^{*}(-0.53$ to -0.06$)$ & - & $-0.31^{* *}(-0.52$ to -0.10$)$ \\
\hline \multicolumn{5}{|l|}{ Random effects } \\
\hline Residual variance & $35.77^{* * *}$ (34.23 to 37.3$)$ & $35.02^{* * *}$ (33.51 to 36.54$)$ & $35.77^{* * *}(34.25$ to 37.29$)$ & $34.94^{* * *}$ (33.45 to 36.42 ) \\
\hline Intercept variance & $177.95^{* * *}(170.31$ to 185.58$)$ & $46.91^{* * *}$ (43.70 to 50.11$)$ & $144.21^{* * *}(137.72$ to 150.71$)$ & $39.66^{* * *}$ (36.75 to 42.58 ) \\
\hline Slope variance & $26.26^{* * *}(12.55$ to 39.98$)$ & $2.31^{* * *}$ (1.27 to 3.34$)$ & $23.66^{* * *}(12.24$ to 35.08$)$ & $1.88^{* *}$ (0.81 to 2.95$)$ \\
\hline Intercept/slope correlation & $0.69^{* * *}$ & -0.30 & $0.67^{* * *}$ & -0.12 \\
\hline Intercepts correlation & \multicolumn{2}{|c|}{-0.02} & \multicolumn{2}{|c|}{0.02} \\
\hline Slopes correlation & \multicolumn{2}{|c|}{-0.11} & \multicolumn{2}{|c|}{-0.02} \\
\hline Alcohol intercept, MCS & \multicolumn{2}{|c|}{-0.05} & \multicolumn{2}{|c|}{-0.06} \\
\hline
\end{tabular}
slope correlation

LCS, latent change score; MCS, mental health component score.

*** $P<0.001 ; * * P<0.01 ; * P<0.05$.

${ }^{a} n=6,330$

${ }^{b}$ Fully adjusted = age (centered around the sample mean), sex (male referent group), ethnicity (white (referent) versus non-white), socioeconomic status (defined by most recent recorded employment grade - entered as a linear term with high (referent), intermediate and low categories), marital status (married/cohabiting (referent) versus other), highest educational qualification (University (referent), post-secondary, secondary or no qualifications - entered as a continuous variable), economic activity (active (referent) versus inactive (merging retired and unemployed groups together)), social network (centered around the mean score), current smoking status (no (referent) versus yes), level of physical activity (active (referent), moderately active or low - entered as a linear term), CAGE caseness (no case (referent) versus case), use of anti-depressant medication was also controlled for (no (referent) versus current), self-reported long-standing physical illness (no (referent) versus yes), belonging to the lowest sex-specific SF-36 physical health component quartile (no (referent) versus yes), known diabetes (no (referent) versus yes), coronary heart disease (no (referent) versus yes), stroke (no (referent) versus yes), transient ischemic attack (no (referent) versus yes), total serum cholesterol (centered around the sample mean), systolic and diastolic blood pressure (centered around their mean values), a resting heart rate $>80$ beats/minute (no (referent) versus yes) and body mass index (centered around the sample mean).

and high alcohol consumption on the previous occasion had a shallower decline in their consumption than those with good mental health drinking the same amount. This indicates that in addition to fuelling increases in alcohol consumption among low-level consumers, poor mental health may also be a maintaining factor for heavy alcohol consumption.

\section{Comparison with other work}

Our findings contradict the most recently published review on the relationship between alcohol use and depression [10], which concluded that increasing involvement with alcohol raises the risk of depression by two-fold. This review was, however, met with criticism $[64,65]$ for primarily being based on previous work by the authors themselves [9]. Furthermore, the review focused on alcohol-use disorders and major depression. Our work is therefore not directly comparable. As outlined earlier, we chose to focus on sub-syndrome symptoms of mental health and alcohol consumption (not problem consumption) as there has been a distinct lack of work exploring actual alcohol consumption (that is, what people drink) in this relationship; previous interest has largely been on the relationship between alcohol-use disorders and major depression. This makes drawing comparisons between our work and others complicated. It may be that there is something about the symptoms of problematic alcohol consumption that increases the risk of having $[6,7,66-71]$ or developing $[9,10,72,73]$ depression, independent of the amount of alcohol consumed $[46,74]$. Recent work has shown that individuals who self-medicate symptoms of anxiety [75] or depression [12] with alcohol have an increased risk of developing (persistent) alcohol dependence. Therefore, it could be that the relationship we observed is part of a larger complex system involving a transition from sub-syndromal symptoms of mental health influencing changes in alcohol consumption (as in our analyses) until a certain threshold is reached, at which symptoms of alcohol dependence take over and increase the risk of developing clinical disorders $[9,10]$; that is, there are two separate dynamic systems at play that influence alcohol consumption and mental health pre and post clinical disorder.

\section{Strengths and weaknesses}

The approach that we took to modeling the relationship between alcohol use and mental health longitudinally 
Table 4 Fixed effect parameter estimates (95\% confidence intervals) for other LCS model specifications of weekly alcohol consumption and mental health symptoms in the Whitehall II study ${ }^{a}$

\begin{tabular}{|c|c|c|c|c|}
\hline & \multicolumn{2}{|l|}{ Age and sex adjusted } & \multicolumn{2}{|l|}{ Fully adjusted $^{\mathbf{b}}$} \\
\hline & Alcohol & MCS & Alcohol & MCS \\
\hline \multicolumn{5}{|l|}{ Baseline } \\
\hline Intercept & $17.15^{* * *}(16.73$ to 17.57$)$ & $51.57^{* * *}$ (51.31 to 51.82$)$ & $17.63^{* * *}$ (16.69 to 18.57$)$ & $53.46^{* * *}$ (52.86 to 54.05$)$ \\
\hline Slope (a) & $4.82^{* * *}$ (3.26 to 6.39 ) & $5.34(-8.16$ to 18.85$)$ & $5.22^{* * *}$ (3.56 to 6.89) & 7.77 (-4.69 to 20.24$)$ \\
\hline Autoproportional ( $\beta$ ) & $-0.43^{* * *}(-0.53$ to -0.33$)$ & $-0.08(-0.34$ to 0.18$)$ & $-0.42^{* * *}(-0.52$ to -0.33$)$ & $-0.12(-0.36$ to 0.11$)$ \\
\hline Coupling $(\gamma)$ & - & - & - & - \\
\hline \multicolumn{5}{|l|}{ Alcohol $\rightarrow \triangle \mathrm{MCS}$ model } \\
\hline Intercept & $17.15^{* * *}(16.73$ to 17.57$)$ & $51.57^{* * *}(51.31$ to 51.83$)$ & $17.63^{* * *}$ (16.7 to 18.57$)$ & $53.47^{* * *}$ (52.87 to 54.06 ) \\
\hline Slope (a) & $4.83^{* * *}$ (3.26 to 6.39 ) & $7.86(-8.21$ to 23.94$)$ & $5.23^{* * *}$ (3.56 to 6.89 ) & $10.82(-3.90$ to 25.55$)$ \\
\hline Autoproportional ( $\beta$ ) & $-0.43^{* * *}(-0.53$ to -0.33$)$ & $-0.12(-0.41$ to 0.17$)$ & $-0.43^{* * *}(-0.52$ to -0.33$)$ & $-0.17(-0.42$ to 0.09$)$ \\
\hline Coupling $(\gamma)$ & $-0.03(-0.15$ to 0.09$)$ & - & $-0.04(-0.15$ to 0.08$)$ & - \\
\hline \multicolumn{5}{|l|}{ Reciprocal $\Delta$ model } \\
\hline Intercept & $17.11^{* * *}(16.69$ to 17.54$)$ & $51.55^{* * *}(51.29$ to 51.81$)$ & $17.59^{* * *}$ (16.65 to 18.53$)$ & $53.42^{* * *}$ (52.83 to 54.02 ) \\
\hline Slope (a) & $21.49^{* *}$ (9.07 to 33.92) & $8.72(-6.03$ to 23.47$)$ & $23.20^{* * *}(11.42$ to 34.99$)$ & 11.05 (-2.70 to 24.79$)$ \\
\hline Autoproportional ( $\beta$ ) & $-0.50^{* * *}(-0.60$ to -0.40$)$ & $-0.13(-0.40$ to 0.14$)$ & $-0.50^{* * *}(-0.59$ to -0.40$)$ & $-0.17(-0.41$ to 0.08$)$ \\
\hline Coupling $(\gamma)$ & $-0.05(-0.16$ to 0.06$)$ & $-0.30^{* *}(-0.52$ to -0.07$)$ & $-0.06(-0.16$ to 0.05$)$ & $-0.31^{* *}(-0.52$ to -0.11$)$ \\
\hline
\end{tabular}

LCS, latent change score; MCS, mental health component score.

*** $P<0.001 ;{ }^{* *} P<0.01 ;{ }^{*} P<0.05$.

${ }^{a} n=6,330$.

${ }^{\mathrm{b}}$ Fully adjusted = age (centered around the sample mean), sex (male referent group), ethnicity (white (referent) versus non-white), socioeconomic status (defined by most recent recorded employment grade - entered as a linear term with high (referent), intermediate and low categories), marital status (married/cohabiting (referent) versus other), highest educational qualification (University (referent), post-secondary, secondary or no qualifications - entered as a continuous variable), economic activity (active (referent) versus inactive (merging retired and unemployed groups together)), social network (centered around the mean score), current smoking status (no (referent) versus yes), level of physical activity (active (referent), moderately active or low - entered as a linear term), CAGE caseness (no case (referent) versus case), use of anti-depressant medication was also controlled for (no (referent) versus current), self-reported long-standing physical illness (no (referent) versus yes), belonging to the lowest sex-specific SF-36 physical health component quartile (no (referent) versus yes), known diabetes (no (referent) versus yes), coronary heart disease (no (referent) versus yes), stroke (no (referent) versus yes), transient ischemic attack (no (referent) versus yes), total serum cholesterol (centered around the sample mean), systolic and diastolic blood pressure (centered around their mean values), a resting heart rate $>80$ beats per minute (no (referent) versus yes) and body mass index (centered around the sample mean).

utilized multiple measurement occasions to model change in both variables over time, which is known to improve the accuracy of estimated change [58,76]. Previous work has also shown that it is important to consider variability in alcohol consumption [77], and the LCS model methodology directly incorporated individual change both in the total weekly alcohol consumption and in mental health. Furthermore, the method we used allowed for the effect of alcohol consumption on mental health and vice versa to be estimated simultaneously in the same model.

There are, however, several limitations of our study. First, data from phase 5 were used as the starting point, and it is possible that selective attrition may have occurred between the 'true' baseline (phase 1) and the baseline used in these analyses. This would result in a healthier cohort of participants being used to estimate the final model parameters, reducing the generalizability of the findings $[78,79]$. Similarly, we used data from the Whitehall II cohort of British civil servants, which is not a representative sample of the general population. Work published using Whitehall II data has been highly influential in epidemiology and public health, shaping research agendas on social inequalities in health [80] and improving the understanding of the etiology of disease [81] but this limitation should be noted when considering the generalizability of our findings.

Second, one of the major concerns in alcohol epidemiology is measurement error in self-reported alcohol consumption [82]. It is acknowledged that self-reported measures of consumption are likely to be biased [82-88], and therefore effect estimates obtained may actually be underestimates of the true association of interest. The use of latent variables (upon which LCS models are based; see Additional file 1) has been advocated in the field of alcohol epidemiology [89] to account for this known measurement error. Additionally, the MCS scale of the SF-36 is not solely concerned with psychiatric symptoms but also with mental health-related quality of life (although evidence exists to suggest that high MCS scores are associated with clinical depression $[40,90,91])$. It is possible that the relationship between alcohol intake and mental health might differ if other psychiatric questionnaires were used to define symptoms of mental health, or if the distinction was made between symptoms of depression and anxiety. However, it is argued that in practice it is 


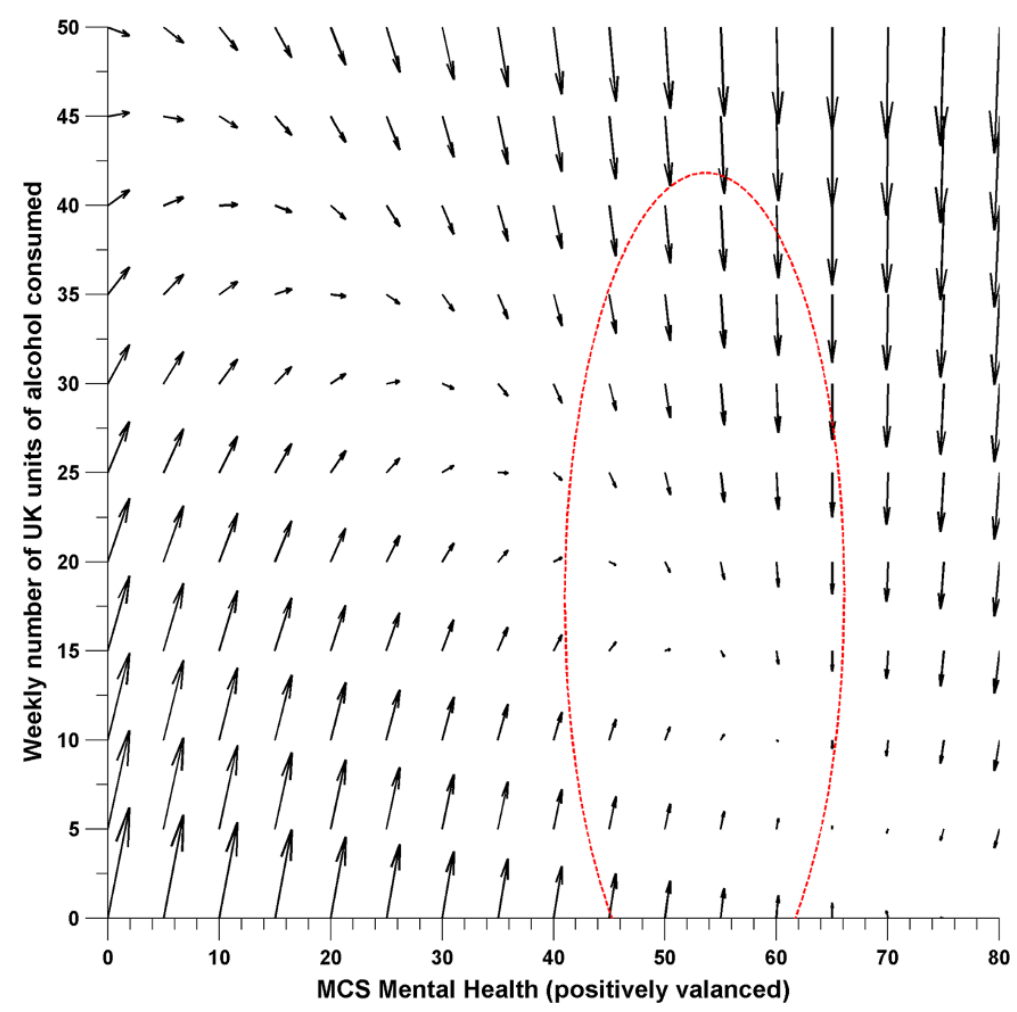

Figure 2 Vector field showing joint movements between weekly alcohol consumption and mental health scores in Whitehall II as a function of the mental health producing change in weekly alcohol consumption system. Ellipsoid reflects $95 \%$ of the data.

difficult to effectively determine specific characteristics of depression from symptoms of, for example, anxiety using self-report measures of symptoms because of the considerable heterogeneity of symptoms between disorders (that is, self-reported symptoms often reflect a comorbidity between depression and other mood/stress-related disorders [92-95]). This has led some investigators to conclude that self-report measures of mental health symptoms at a population level merely reflect a single underlying latent construct of psychological distress [96-99].

Another issue concerning the main measures used in this study is that they refer to different time periods; information on alcohol consumption pertained to the previous week whereas information on mental health symptoms referred to the previous 4 weeks. It is possible that this discrepancy in the period of reference may have biased our findings. For example, smaller studies looking at the relationship between mood and alcohol on a daily basis have shown that increased alcohol consumption is associated with decreased happiness on the following day, and that symptoms of sadness are associated with decreased consumption on the next day [100]. These findings contrast with our own, and highlight the importance of the timeframe used in determining the best-fitting temporal sequence between alcohol consumption and mental health.
Furthermore, the competing models we specified allowed only for the previous occasion's alcohol and/or mental health score to influence change in the alternative variable by the next occasion. It is plausible that the relationship might have differed if we had allowed for longer lag specifications, as it may be that the relationship between alcohol intake and mental health takes longer to manifest (that is, the current specification of a single cross-lagged effect may fit the relationship between mental health influencing alcohol intake better than the relationship between alcohol consumption influencing mental health symptoms).

Additionally, there was greater variation in the measure of weekly alcohol intake than in that of mental health. It could be argued that this could also be a possible explanation as to why alcohol consumption was not found to be significantly related to changes in mental health. It may be that within a dynamic system that it is more difficult to effectively predict changes in one variable using a highly erratic alternative exposure. It is conceivable that the reciprocal model might have been of best fit had both measures been relatively stable over time.

A further methodological limitation is that we controlled only for baseline covariate values, and it is possible that their values changed over time. For example, comorbidities may have developed after the first measurement occasion. Health behaviors such as physical activity and smoking 
could also vary over time, and the changing status of these variables could all be confounders of the subsequent effects of alcohol on mental health and vice versa. However, factoring in changes in the covariate structure over time could be problematic within the current framework, because changes in some values, for example, systolic blood pressure, could be a direct consequence of previous alcohol consumption or mental health status, and thus be considered as intermediate confounders [101].

\section{Implications and directions for future work}

We identified that the dominant process underlying the dynamic relationship between alcohol consumption and mental health at a population level is mental health. Consequently, it could be inferred that targeting interventions to those with poor mental health (as well as introducing measures to ensure that those with normal/ good mental health do not deteriorate) would have a beneficial effect in terms of reducing heavy drinking. This may also elicit favorable knock-on effects in terms of improving general physical health and reducing the risk of chronic diseases, as heavy drinking itself is associated with an increased risk of a range of health problems [102,103] including cardiovascular disease [104-109], cancer, [110,111] and mortality $[47,112-114]$. Furthermore, the finding that mental health affects alcohol consumption may shed some light on the growing literature examining common mental disorders as risk factors for cardiovascular disease [115-119] and all-cause mortality [120-122], because alcohol consumption may be one of many mediators in this relationship.

This work provides further support that on-going efforts to improve mental health at a population level are vital to public health $[123,124]$. The proposed implementation strategy [124] seeks both to tackle he social determinants of mental health [125] and to target individuals who are at high risk. To do so, a number of avenues will be pursued, including tackling inequalities in access to services (and ensuring equality in the level of service provided). In addition, conscious efforts are being made to tackle the stigma surrounding mental health issues; perhaps if individuals feel more comfortable talking about their mental health problems or seeking treatment for them, then they will not turn to alcohol as a form of self-medication.

Others may, however, be more cynical of our findings and take them to indicate that 1) consuming large amounts of alcohol is acceptable as it does not increase the risk of developing mental health problems, and 2) that it is reasonable to self-medicate with alcohol in response to psychological distress, as it will not worsen symptoms. However, it would be unwise to use our findings as a justification for drinking in a hazardous manner. Although a person's mental health may not worsen, as highlighted above, increased alcohol consumption would heighten their risk of developing other disorders.

Regarding future work, it is important to examine the role of drinking pattern as well as to provide closer scrutiny of age (e.g. adolescent and elderly populations), sex, socioeconomic, and cultural differences in the dynamic relationship between alcohol consumption and mental health. It is also important that subsequent studies should examine the extent to which time-varying/modified confounding may explain the association observed using appropriate analytic methods [101]. Furthermore, it is also imperative that potential physiological and psychosocial mechanisms, both occurring alongside and precipitating (immediately or earlier in life) the parallel development of both trajectories are studied. This has been acknowledged by others in the field $[10,64,65]$. Understanding the factors that trigger increased alcohol consumption in the presence of poor mental health will allow for more effective interventions to be developed, both in terms of treatment and primary prevention.

\section{Conclusions}

Mental health appears to be the leading indicator of change in the dynamic longitudinal relationship between mental health and weekly alcohol consumption in this middleaged, mostly white, male, and well-educated sample of individuals. In addition to increasing alcohol intake among low-level consumers, poor mental health may also be a maintaining factor for sustained high alcohol intake in heavy alcohol consumers. Our findings therefore indicate that on-going efforts to improve mental health at a population level may also help to reduce hazardous alcohol consumption. Future work should seek to examine whether there are critical levels of alcohol consumption at which different dynamic relationships operate between alcoholrelated behavior and mental health, specifically focusing on heterogeneities in the dynamic processes between alcohol intake and symptoms of alcohol dependence, and mental health pre and post clinical disorder to try and better capture the possible discontinuous progression from subsyndrome behavior to clinically relevant outcomes.

\section{Additional files}

Additional file 1: Description of latent change score methodology. Figure S1A. A path diagram representing a bivariate latent change score model. Table S1A - Definition of parameters depicted in Additional file 1: Figure S1A

Additional file 2: Table S2A. - Detailed parameter estimates ( $95 \%$ confidence intervals) for all latent change score (LCS) model specifications of weekly alcohol consumption and mental health symptoms in the Whitehall II study.

Additional file 3: Description of covariate coefficients $(95 \% \mathrm{CI})$ for fully-adjusted mental health component score (MCS) producing change in alcohol consumption model. Table S3A - Covariate 
coefficients $(95 \% \mathrm{Cl})$ for fully-adjusted MCS producing change in alcohol consumption model.

\section{Competing interests}

None of the authors have any competing interests.

\section{Author contributions}

$\mathrm{SB}$ and $\mathrm{AB}$ devised the research question. SB analysed the data and completed the first draft of the manuscript. $A B$ provided important additional comments on the initial manuscript. Both $S B$ and $A B$ agreed on the decision to submit the final manuscript. SB had full access to all of the data in the study, and takes responsibility for the integrity of the data and the accuracy of the data analysis. All authors read and approved the final manuscript.

\section{Acknowledgements}

We thank all participating civil service departments and their welfare, personnel, and establishment officers; the Occupational Health and Safety Agency; the Council of Civil Service Unions; all participating civil servants in the Whitehall II study; and all members of the Whitehall II study team. This work was supported by a UK Economic and Social Research Council PhD Studentship (SB) and the European Research Council (309337, PI: Britton, http://www.ucl.ac.uk/alcohol-lifecourse). The Whitehall II study is supported by grants from the Medical Research Council (G0902037), British Heart Foundation (RG/07/008/23674), Stroke Association, National Heart Lung and Blood Institute (5RO1 HL036310), and National Institute on Aging (5RO1AG13196 and 5RO1AG034454). The funders had no role in study design, data collection and analysis, decision to publish, or preparation of the manuscript.

Received: 27 January 2014 Accepted: 28 April 2014

Published: 3 June 2014

\section{References}

1. World Health Organisation: Alcohol in the European Union. Consumption, Harm and Policy Approaches. Copenhagen, Denmark: World Health Organisation Regional Office for Europe; 2012:1-161.

2. Rehm J, Mathers C, Popova S, Thavorncharoensap M, Teerawattananon Y, Patra J: Global burden of disease and injury and economic cost attributable to alcohol use and alcohol-use disorders. Lancet 2009, 373:2223-2233.

3. Horton R: Launching a new movement for mental health. Lancet 2007 370:806

4. Patel V, Jenkins R, Lund C, The PLoS Medicine Editors: Putting evidence into practice: the PLoS medicine series on global mental health practice. PLoS Med 2012, 9:e1001226.

5. Ferrari AJ, Charlson FJ, Norman RE, Patten SB, Freedman G, Murray CJL, Vos T, Whiteford HA: Burden of depressive disorders by country, sex, age, and year: findings from the Global Burden of Disease Study 2010. PLoS Med 2013, 10:e1001547.

6. Grant BF, Harford TC: Comorbidity between DSM-IV alcohol use disorders and major depression: results of a national survey. Drug Alcohol Depend 1995, 39:197-206.

7. Boschloo L, Vogelzangs N, van den Brink W, Smit JH, Veltman DJ, Beekman ATF, Penninx BWJH: Alcohol use disorders and the course of depressive and anxiety disorders. Br J Psychiatry 2012, 200:476-484.

8. Wang J, Patten SB: Alcohol consumption and major depression: findings from a follow-up study. Can J Psychiatry 2001, 46:632-638.

9. Fergusson DM, Boden JM, Horwood LJ: Tests of causal links between alcohol abuse or dependence and major depression. Arch Gen Psychiatry 2009, 66:260-266

10. Boden JM, Fergusson DM: Alcohol and depression. Addiction 2011 106:906-914.

11. Hartka E, Johnson BM, Leino EV, Motoyoshi M, Temple MT, Fillmore KM: A meta-analysis of depressive symptomatology and alcohol consumption over time. Br J Addict 1991, 86:1283-1298.

12. Crum RM, Mojtabai R, Lazareck S, Bolton JM, Robinson J, Sareen J, Green KM, Stuart EA, La Flair L, Alvanzo AAH, Storr CL: A prospective assessment of reports of drinking to self-medicate mood symptoms with the incidence and persistence of alcohol dependence. JAMA Psychiatry 2013, 70:718-726.
13. Gea A, Beunza J, Estruch R, Sanchez-Villegas A, Salas-Salvado J, Buil-Cosiales P, Gomez-Gracia E, Covas M-I, Corella D, Fiol M, Aros F, Lapetra J, Lamuela-Raventos R-M, Warnberg J, Pinto X, Serra-Majem L, Martinez-Gonzalez M, for the PREDIMED GROUP: Alcohol intake, wine consumption and the development of depression: the PREDIMED study. BMC Med 2013, 11:192.

14. Mueser KT, Drake RE, Wallach MA: Dual diagnosis: a review of etiological theories. Addict Behav 1998, 23:717-734.

15. Bühler M, Mann K: Alcohol and the human brain: a systematic review of different neuroimaging methods. Alcohol Clin Exp Res 2011, 35:1771-1793.

16. Bennett MR: The prefrontal-limbic network in depression: A core pathology of synapse regression. Prog Neurobiol 2011, 93:457-467.

17. Olesen PJ, Gustafson DR, Simoni M, Pantoni L, Ostling S, Guo X, Skoog I: Temporal lobe atrophy and white matter lesions are related to major depression over 5 years in the elderly. Neuropsychopharmacol 2010 35:2638-2645

18. Nobuhara K, Okugawa G, Sugimoto T, Minami T, Tamagaki C, Takase K, Saito $Y$, Sawada S, Kinoshita T: Frontal white matter anisotropy and symptom severity of late-life depression: a magnetic resonance diffusion tensor imaging study. J Neurol Neurosurg Psychiatry 2006, 77:120-122.

19. Petty F: GABA and mood disorders: a brief review and hypothesis. J Affect Disorders 1995, 34:275-281

20. Brambilla P, Perez J, Barale F, Schettini G, Soares JC: GABAergic dysfunction in mood disorders. Mol Psychiatry 2003, 8:721-737.

21. Dunlop BW, Nemeroff CB: The role of dopamine in the pathophysiology of depression. Arch Gen Psychiatry 2007, 64:327-337.

22. Jans LAW, Riedel WJ, Markus CR, Blokland A: Serotonergic vulnerability and depression: assumptions, experimental evidence and implications. Mol Psychiatry 2006, 12:522-543.

23. Pietraszek MH, Urano T, Sumioshi K, Serizawa K, Takahashi S, Takada Y, Takada A: Alcohol-induced depression: involvement of serotonin. Alcohol Alcohol 1991, 26:155-159.

24. National Health and Medical Research Council: Alcohol and health in Australia. http://www.nhmrc.gov.au/your-health/alcohol-guidelines/ alcohol-and-health-australia]

25. Kung WW: The interwined relationship between depression and marital distress: elements of marital therapy conducive to effect treatment outcome. J Marital Fam Ther 2000, 26:51-63.

26. Flint E, Bartley M, Shelton N, Sacker A: Do labour market status transitions predict changes in psychological well-being? J Epidemiol Community Health 2013, 67:796-802

27. Brown SA, Schuckit MA: Changes in depression among abstinent alcoholics. J Stud Alcohol Drug 1988, 49:412.

28. Conger JJ: Reinforcement theory and the dynamics of alcoholism Q J Stud Alcohol 1956, 17:296-305.

29. Abbey A, Smith MJ, Scott RO: The relationship between reasons for drinking alcohol and alcohol consumption: an interactional approach. Addict Behav 1993, 18:659-670.

30. Carpenter KM, Hasin DS: Drinking to cope with negative affect and DSM-IV alcohol use disorders: a test of three alternative explanations. J Stud Alcohol 1999, 60:694-704.

31. Holahan CJ, Moos RH, Holahan CK, Cronkite RC, Randall PK: Drinking to cope and alcohol use and abuse in unipolar depression: a 10-year model. J Abnorm Psychol 2003, 112:159-165.

32. Holahan CJ, Moos RH, Holahan CK, Cronkite RC, Randall PK: Drinking to cope, emotional distress and alcohol use and abuse: a ten-year model. J Stud Alcohol 2001, 62:190-198.

33. Conner KR, Pinquart M, Gamble SA: Meta-analysis of depression and substance use among individuals with alcohol use disorders. J Subst Abuse Treat 2009, 37:127-137.

34. Meyer RE: Psychopathology and Addictive Disorders. New York, USA: Guildford Press; 1986.

35. Ferrer $E$, McArdle JJ: Longitudinal modeling of developmental changes in psychological research. Curr Dir Psychol Sci 2010, 19:149-154.

36. National Institute for Health and Clinical Excellence: CG90 Depression in Adults: Full Guidance. The British Psychological Society and The Royal College of Psychiatrists; 2009:707.

37. Haynes JC, Farrell M, Singleton N, Meltzer H, Araya R, Lewis G, Wiles NJ: Alcohol consumption as a risk factor for anxiety and depression: results from the longitudinal follow-up of the National Psychiatric Morbidity Survey. Br J Psychiatry 2005, 187:544-551. 
38. Marmot M, Brunner E: Cohort profile: the Whitehall II study. Int J Epidemiol 2005, 34:251-256

39. Ware J, Kosinski M, Keller S: SF-36 ${ }^{\oplus}$ Physical and Mental Health Summary Scales: A User's Manual. Boston, MA: The Health Institute; 1994

40. Ware JE, Kosinski M, Bayliss MS, McHorney CA, Rogers WH, Raczek A: Comparison of methods for the scoring and statistical analysis of SF-36 health profile and summary measures: summary of results from the medical outcomes study. Med Care 1995, 33:AS264-AS279.

41. Ware JE, Sherbourne CD: The MOS 36-Item Short-Form Health Survey (SF-36): I. Conceptual framework and item selection. Med Care 1992, 30:473-483

42. Jenkinson C, Layte R, Lawrence K: Development and testing of the medical outcomes study 36-item Short Form Health Survey summary scale scores in the United Kingdom: results from a large-scale survey and a clinical trial. Med Care 1997, 35:410-416.

43. Berkman LF, Syme SL: Social networks, host resistance and mortality: a nine year follow-up of Alameda county residents. Am J Epidemiol 1979 109:186-204.

44. Stringhini S, Sabia S, Shipley M, Brunner E, Nabi H, Kivimaki M, Singh-Manoux A: Association of socioeconomic position with health behaviors and mortality. JAMA 2010, 303:1159-1166.

45. Ewing JA: Detecting alcoholism: the CAGE questionnaire. JAMA 1984 252:1905-1907.

46. Bulloch A, Lavorato D, Williams J, Patten S: Alcohol consumption and major depression in the general population: the critical importance of dependence. Depress Anxiety 2012, 29:1058-1064.

47. Shaper AG, Wannamethee G, Walker M: Alcohol and mortality in British men: explaining the U-shaped curve. Lancet 1988, 332:1267-1273.

48. Fillmore KM, Stockwell T, Chikritzhs T, Bostrom A, Kerr W: Moderate alcohol use and reduced mortality risk: systematic error in prospective studies and new hypotheses. Ann Epidemiol 2007, 17:S16-S23.

49. Sacker A, Head J, Gimeno D, Bartley M: Social inequality in physical and mental health comorbidity dynamics. Psychosom Med 2009, 71:763-770.

50. Britton A, Milne B, Butler T, Sanchez-Galvez A, Shipley M, Rudd A, Wolfe C, Bhalla A, Brunner E: Validating self-reported strokes in a longitudinal UK cohort study (Whitehall II): Extracting information from hospital medical records versus the Hospital Episode Statistics database. BMC Med Res Methodol 2012, 12:83.

51. Hemingway $H$, Shipley $M$, Britton A, Page M, Macfarlane P, Marmot M: Prognosis of angina with and without a diagnosis: 11 year follow up in the Whitehall II prospective cohort study. BMJ 2003, 327.

52. Fuster V, Rydén LE, Asinger RW, Cannom DS, Crijns HJ, Frye RL, Halperin JL, Kay GN, Klein WW, Lévy S, McNamara RL, Prystowsky EN, Wann LS, Wyse DG: ACC/AHA/ESC guidelines for the management of patients with atrial fibrillation: executive summary: a report of the American College of Cardiology/American Heart Association Task Force on Practice Guidelines and the European Society of Cardiology Committee for Practice Guidelines and Policy Conferences (Committee to Develop Guidelines for the Management of Patients With Atrial Fibrillation). Circulation 2001, 104:2118-2150.

53. Grimm KJ: Multivariate longitudinal methods for studying developmental relationships between depression and academic achievement. Int J Behav Dev 2007, 31:328-339.

54. McArdle JJ, Grimm KJ: Five steps in latent curve and latent change score modeling with longitudinal data. In Longitudinal Research with Latent Variables. Heidelberg, Berlin: Springer; 2010:245-273.

55. McArdle JJ, Hamagami F: Latent difference score structural models for linear dynamic analyses with incomplete longitudinal data. In New Methods for the Analysis of Change. 1st edition. Washington, DC: American Psychological Association; 2001:137-176.

56. McArdle JJ, Hamgami F, Jones K, Jolesz F, Kikinis R, Spiro A, Albert MS: Structural modeling of dynamic changes in memory and brain structure using longitudinal data from the normative aging study. J Gerontol B Psychol Sci Soc Sci 2004, 59:294-304.

57. Hamagami F, McArdle J: Advanced studies of individual differences linear dynamic models for longitudinal data analysis. In New Developments and Techniques in Structural Equation Modeling. Mahwah, New Jersey: Lawrence Erlbaum Associates, Inc; 2001:203-246.

58. Bollen KA, Curran PJ: Latent Curve Models: A Structural Equation Perspective. New Jersey: John Wiley \& Sons, Inc; 2006.
59. Hu L, Bentler PM: Cut off criteria for fit indexes in covariance structure analysis: Conventional criteria versus new alternatives. Struct Equ Modeling 1999, 6:1-55.

60. Muthén LK, Muthén BO: Mplus User's Guide. 6th edition. Muthén \& Muthén: Los Angeles, CA; 2010.

61. Raykov T: Analysis of longitudinal studies with missing data using covariance structure modeling with full-information maximum likelihood. Struct Equ Modeling 2005, 12:493-505.

62. McArdle J: Longitudinal dynamic analyses of cognition in the health and retirement study panel. AstA Adv Stat Anal 2011, 95:453-480.

63. Boker SM, McArdle JJ: Statistical vector field analysis applied to mixed cross-sectional and longitudinal data. Exp Aging Res 1995, 21:77-93.

64. Flensborg-Madsen T: Alcohol use disorders and depression - the chicken or the egg? Addiction 2011, 106:916-918.

65. Conner KR: Clarifying the relationship between alcohol and depression. Addiction 2011, 106:915-916.

66. Swendsen JD, Merikangas KR, Canino GJ, Kessler RC, Rubio-Stipec M, Angst $\mathrm{J}$ : The comorbidity of alcoholism with anxiety and depressive disorders in four geographic communities. Compr Psychiatry 1998, 39:176-184

67. Burns $L$, Teesson M: Alcohol use disorders comorbid with anxiety, depression and drug use disorders: Findings from the Australian National Survey of Mental Health and Well Being. Drug Alcohol Depend 2002, 68:299-307.

68. Smith GW, Shevlin M: Patterns of alcohol consumption and related behaviour in Great Britain: a latent class analysis of the alcohol use disorder identification test (AUDIT). Alcohol Alcohol 2008, 43:590-594.

69. Bolton JM, Robinson J, Sareen J: Self-medication of mood disorders with alcohol and drugs in the National Epidemiologic Survey on Alcohol and Related Conditions. J Affect Disord 2009, 115:367-375.

70. Zhan W, Shaboltas A, Skochilov R, Kozlov A, Krasnoselskikh T: Gender differences in the relationship between alcohol use and depressive symptoms in St. Petersburg, Russia. J Addict Res Ther 2012, 3:2.

71. Crum RM, Storr CL, Chan Y: Depression syndromes with risk of alcohol dependence in adulthood: a latent class analysis. Drug Alcohol Depend 2005, 79:71-81.

72. Flensborg-Madsen T, Mortensen EL, Knop J, Becker U, Sher L, Grønbæk M: Comorbidity and temporal ordering of alcohol use disorders and other psychiatric disorders: results from a Danish register-based study. Compr Psychiatry 2009, 50:307-314.

73. Boschloo L, van den Brink W, Penninx BWJH, Wall MM, Hasin DS: Alcohol-use disorder severity predicts first-incidence of depressive disorders. Psychol Med 2012, 42:695-703.

74. Boschloo L, Vogelzangs N, van den Brink W, Smit JH, Veltman DJ, Beekman ATF, Penninx BWJH: Authors' reply. Br J Psychiatry 2012, 201:326-327.

75. Crum RM, La Flair L, Storr CL, Green KM, Stuart EA, Alvanzo AAH, Lazareck S, Bolton JM, Robinson J, Sareen J, Mojtabai R: Reports of drinking to self-medicate anxiety symptoms: longitudinal assessment for subgroups of individuals with alcohol dependence. Depress Anxiety 2013, 30:174-183.

76. Singer JD, Willett JB: Applied Longitudinal Data Analysis: Modeling Change and Event Occurrence. New York: Oxford University Press; 2003.

77. Britton A, Marmot MG, Shipley MJ: How does variability in alcohol consumption over time affect the relationship with mortality and coronary heart disease? Addiction 2010, 105:639-645.

78. Hernán MA, Hernández-Díaz S, Robins JM: A structural approach to selection bias. Epidemiology 2004, 15:615-625.

79. Stockwell T, Chikritzhs T: Commentary: another serious challenge to the hypothesis that moderate drinking is good for health? Int J Epidemiol 2013, 42:1792-1794.

80. Marmot MG, Stansfeld S, Patel C, North F, Head J, White I, Brunner E, Feeney A, Smith GD: Health inequalities among British civil servants: the Whitehall II study. Lancet 1991, 337:1387-1393.

81. Tabák AG, Jokela M, Akbaraly TN, Brunner EJ, Kivimäki M, Witte DR Trajectories of glycaemia, insulin sensitivity, and insulin secretion before diagnosis of type 2 diabetes: an analysis from the Whitehall II study. Lancet 2009, 373:2215-2221.

82. Klatsky AL: Epidemiology of coronary heart disease-influence of alcohol. Alcohol Clin Exp Res 1994, 18:88-96.

83. Wilsnack SC, Wilsnack RW: International gender and alcohol research: recent findings and future directions. Alcohol Res Health 2002, 26:245-250.

84. Kaskutas LA, Graves K: An alternative to standard drinks as a measure of alcohol consumption. J Subst Abuse 2000, 12:67-78. 
85. Williams GD, Proudfit AH, Quinn EA, Campbell KE: Variations in quantity-frequency measures of alcohol consumption from a general population survey. Addiction 1994, 89:413-420.

86. Bobrova N, West R, Malyutina D, Malyutina S, Bobak M: Gender differences in drinking practices in middle aged and older Russians. Alcohol Alcohol 2010, 45:573-580.

87. Laatikainen $T$, Alho $H$, Vartiainen $E$, Jousilahti $P$, Sillanaukee P, Puska P: Self-reported alcohol consumption and association to carbohydrate-deficient transferrin and gamma-glutamyltransferase in a random sample of the general population in the Republic of Karelia, Russia and in North Karelia, Finland. Alcohol Alcohol 2002, 37:282-288.

88. Kiechl S, Willeit J, Egger G, Oberhollenzer M, Aichner F: Alcohol consumption and carotid atherosclerosis: evidence of dose- dependent atherogenic and antiatherogenic effects. Results from the Bruneck Study. Stroke 1994, 25:1593-1598.

89. Prisciandaro JJ, DeSantis SM, Bandyopadhyay D: Simultaneous modeling of the impact of treatments on alcohol consumption and quality of life in the COMBINE study: a coupled hidden Markov analysis. Alcohol Clin Exp Res 2012, 36:2141-2149.

90. Elliott TE, Renier CM, Palcher JA: Chronic pain, depression, and quality of life: correlations and predictive value of the SF-36. Pain Med 2003, 4:331-339.

91. Tavella R, Air T, Tucker G, Adams R, Beltrame J, Schrader G: Using the Short Form-36 mental summary score as an indicator of depressive symptoms in patients with coronary heart disease. Qual Life Res 2010, 19:1105-1113.

92. Goldberg DP: The Detection of Psychiatric Illness by Questionnaire. London: Oxford University Press; 1972

93. Goldberg DP, Gater R, Sartorius N, Ustun T, Piccinelli M, Gureje O, Rutter C: The validity of two versions of the GHQ in the WHO study of mental illness in general health care. Psychol Med 1997, 27:191-197.

94. Goldberg D, Goodyer I: The Origins and Course of Common Mental Disorders. London: Routledge; 2005

95. Prince M, Patel V, Saxena S, Maj M, Maselko J, Phillips MR, Rahman A: No health without mental health. Lancet 2007, 370:859-877.

96. Clark LA, Watson D: Tripartite model of anxiety and depression: Psychometric evidence and taxonomic implications. J Abnorm Psychol 1991, 100:316-336

97. Clark LA, Watson D, Mineka S: Temperament, personality, and the mood and anxiety disorders. J Abnorm Psychol 1994, 103:103-116.

98. Mineka S, Watson D, Clark LA: Comorbidity of anxiety and unipolar mood disorders. Annu Rev Psychol 1998, 49:377-412.

99. Watson D: Rethinking the mood and anxiety disorders: A quantitative hierarchical model for DSM-V. J Abnorm Psychol 2005, 114:522-536.

100. Harder VS, Ayer LA, Rose GL, Naylor MR, Helzer JE: Alcohol, moods and male-female differences: daily interactive voice response over 6 months. Alcohol Alcohol 2014, 49:60-65.

101. Robins JM, Hernán MÁ, Brumback B: Marginal structural models and causal inference in epidemiology. Epidemiology 2000, 11:550-560.

102. Bell S, Britton A: Alcohol and men's health. Trends Urol Mens Health 2011, 2:9-12.

103. Kelleher M: Drugs and alcohol: physical complications. Psychiatry 2006, 5:442-445.

104. Movva R, Figueredo VM: Alcohol and the heart: To abstain or not to abstain? Int J Cardiol 2013, 164:267-276

105. Roerecke M, Rehm J: The cardioprotective association of average alcohol consumption and ischaemic heart disease: a systematic review and meta-analysis. Addiction 2012, 107:1246-1260.

106. Britton A: Alcohol and heart disease. BMJ 2010, 341:c5957.

107. Ronksley PE, Brien SE, Turner BJ, Mukamal KJ, Ghali WA: Association of alcohol consumption with selected cardiovascular disease outcomes: a systematic review and meta-analysis. BMJ 2011, 342:d671.

108. O'Keefe JH, Bybee KA, Lavie CJ: Alcohol and cardiovascular health: the razor-sharp double-edged sword. J Am Coll Cardiol 2007, 50:1009-1014.

109. Ruidavets J-B, Ducimetière $P$, Evans $A$, Montaye $M$, Haas $B$, Bingham $A$, Yarnell J, Amouyel $P$, Arveiler D, Kee F, Bongard V, Ferrières J: Patterns of alcohol consumption and ischaemic heart disease in culturally divergent countries: the Prospective Epidemiological Study of Myocardial Infarction (PRIME). BMJ 2010, 341:c6077.

110. Boffetta P, Hashibe M: Alcohol and cancer. Lancet Oncol 2006, 7:149-156.

111. Allen NE, Beral V, Casabonne D, Kan SW, Reeves GK, Brown A, Green J: Moderate alcohol intake and cancer incidence in women. $J$ Natl Cancer Inst 2009, 101:296-305.
112. Tomkins S, Collier T, Oralov A, Saburova L, McKee M, Shkolnikov V, Kiryanov $\mathrm{N}$, Leon DA: Hazardous alcohol consumption is a major factor in male premature mortality in a typical Russian city: prospective cohort study 2003-2009. PLoS One 2012, 7:e30274.

113. Rostron B: Alcohol consumption and mortality risks in the USA. Alcohol Alcohol 2012, 47:334-339.

114. Jeong H-G, Kim TH, Lee JJ, Lee SB, Park JH, Huh Y, Chin HJ, Jhoo JH, Lee DY, Woo Jl, Kim KW: Impact of alcohol use on mortality in the elderly: Results from the Korean Longitudinal Study on Health and Aging. Drug Alcohol Depend 2012, 121:133-139.

115. Van der Kooy K, van Hout H, Marwijk H, Marten H, Stehouwer C, Beekman A: Depression and the risk for cardiovascular diseases: systematic review and meta analysis. Int J Geriat Psychiatry 2007, 22:613-626.

116. Nabi H, Kivimäki M, Suominen S, Koskenvuo M, Singh-Manoux A, Vahtera J: Does depression predict coronary heart disease and cerebrovascular disease equally well? The Health and Social Support Prospective Cohort Study. Int J Epidemiol 2010, 39:1016-1024.

117. Rumsfeld JS, Ho PM: Depression and cardiovascular disease: a call for recognition. Circulation 2005, 111:250-253.

118. Ferketich AK, Schwartzbaum JA, Frid DJ, Moeschberger ML: Depression as an antecedent to heart disease among women and men in the NHANES I Study. Arch Intern Med 2000, 160:1261-1268.

119. Stansfeld SA, Fuhrer R, Shipley MJ, Marmot MG: Psychological distress as a risk factor for coronary heart disease in the Whitehall II Study. Int J Epidemiol 2002, 31:248-255

120. Nabi H, Shipley MJ, Vahtera J, Hall M, Korkeila J, Marmot MG, Kivimäki M Singh-Manoux A: Effects of depressive symptoms and coronary heart disease and their interactive associations on mortality in middle-aged adults: the Whitehall II cohort study. Heart 2010, 96:1645-1650.

121. Thomson W: Lifting the shroud on depression and premature mortality: a 49-year follow-up study. J Affect Disord 2011, 130:60-65.

122. Zhang J-P, Kahana B, Kahana E, Hu B, Pozuelo L: Joint modeling of longitudinal changes in depressive symptoms and mortality in a sample of community-dwelling elderly people. Psychosom Med 2009, 71:704-714

123. Royal College of Psychiatrists: No Health without Public Mental Health: The Case for Action. Position Statement. London: Royal College of Psychiatrists; 2010:48.

124. Centre for Mental Health, Department of Health, Mind, NHS Confederation Mental Health Network, Rethink Mental Illness, Turning Point: No Health Without Mental Health: Implementation Framework. 2012:54.

125. The Marmot Review: Fair Society, Healthy Lives: A Strategic Review of Health Inequalities in England Post-2010. 2010:1-242.

doi:10.1186/1741-7015-12-91

Cite this article as: Bell and Britton: An exploration of the dynamic longitudinal relationship between mental health and alcohol consumption: a prospective cohort study. BMC Medicine 2014 12:91.

\section{Submit your next manuscript to BioMed Central and take full advantage of:}

- Convenient online submission

- Thorough peer review

- No space constraints or color figure charges

- Immediate publication on acceptance

- Inclusion in PubMed, CAS, Scopus and Google Scholar

- Research which is freely available for redistribution 